\title{
OVER DE BETEEKENIS VAN SOMMIGE JAVAANSCHE UITDRUKKINGEN
}

In de "Bijdragen tot de taal-, land- en volkenkunde van Nederlandsch-Indië ", uitgegeven door het daarop betrekking hebbende koninklijk Instituut, vierde volgreeks, eerste deel, 3e stuk, komt een stuk voor van den Hoogleeraar H. Kern over de bedoeling van eenige Javaansche woordeu als:

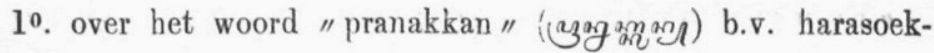

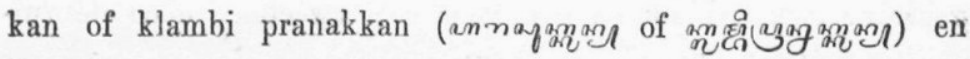

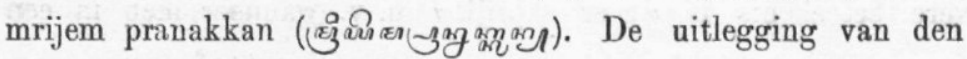

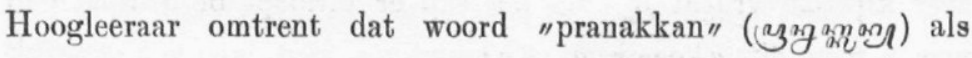
zoude dit "landskind, inboorling". zijn, is volgens mijne bescheiden meening niet geheel juist; de Javaan verstaat door het woord "pranakkan" halfbloed, gemengd ras en "klambi pranakkan" beteekent dus, een baadje dat een half chineesch of half hollandschenz. en half Javaansch model heeft; evenzoo is de "mrijem pranakkan" een kanon dat niet het gewone fatsoen heeft hetwelk de Javaan gewoon is te zien, dat hij beschouwd heeft als inlandsch maaksel, en noch den vorm heeft van Europeesche noch van andere uitheemsche kanonnen, derhalve een gemengd fatsoen van kanon. Men zou "een mortier" een mrijem pranakkan kunuen noemen; wellicht is de bedoelde "mrijem pranakkan " een mortier.

20. "Alapalappan" (annsasmnsas a grondwoord "alap" (annısy) bet. nemen, derhalve "Alapa-

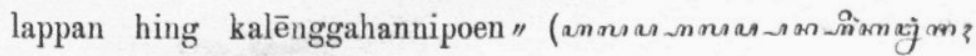


angigam) wordt op bl. 285, r. 2 van de Babad tanah djawi bedoeld: de een neemt de post of bediening van den ander, hetzij door de gezagvoerende personen om te koopen, hetzij eigendunkelijk een ander weg te jagen als anderszins; daarom volgt er op, dat "sakalangkoeng rēsah tataning nagari"

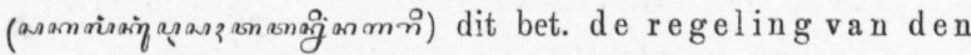
stat is zeer verward.

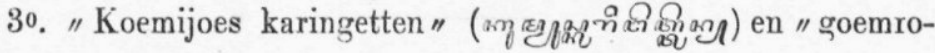

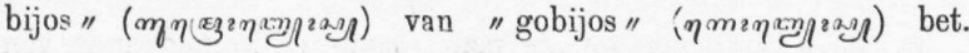
nat worden door het zweet, of beter buitengewoon veel zweeten; de woorden "koemijoes" en "goemrobijos" worden alleen gebruikt voor het zweet, maar b. v. nat wor-

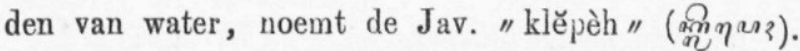

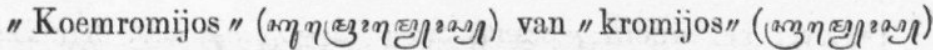
gebruikt men ook nu en dan voor veel zweeten, doch de zuivere beteekenis is "zeer saprijk" b. v. wanneer men in een zeer saprijke vrucht bijt en het sap er uitloopt of druipt, dan noemt men dit "koemromijos "; evenzoo zegt men van een stuk vet vleesch of visch, dat geroosterd wordt en waarvan het vet afdruipt.

40 "Kajoet" (amay tot zich nemen, en aan iets vast binden.

In de "Babad tanah djawi" bì. 547 , r. 6 van o. staat

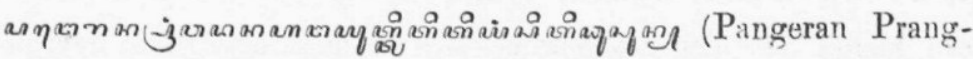
wadånå hangajoetti titijang siti doesoen) dit zou vertaald kunnen worden door "Pangeran Prangwadånå heeft de desa-inwoners bij zich (genomen) laten komen " of beter "verzameld."

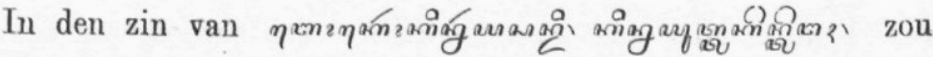

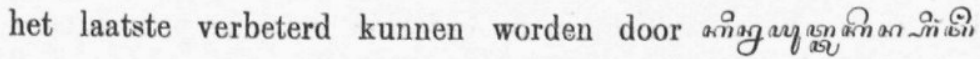
๓ฉ (båkor kinarjo sandi kinajoettaken hing tengah); dit zou vertaald kunuen worden door: " een metalen kom wordt als een verborgen list gebruikt, door die om 't middel (midden) vastgebonden." 


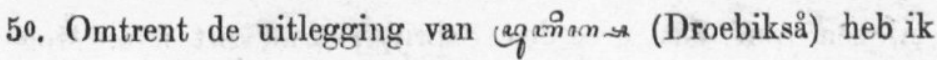
niets op te merken; en

60. Ngoendoeh mantoe ( " ngoendoeh " is plukken, "mantoe" is schoonzoon of schoondochter; de woordelijke bet. zou dan zijn "de schoonzoon of schoondochter plukken." Men zou de bedoeling hiervan kunnen vertalen, door: "de bruid van haar ouderlijk huis halen om bij de ouders van den bruidegom het bruiloftsfeest opnieuw te vieren; echter wordt er niet bij bepaald hoevele dagen na het huwelijk; in de vorstenlanden is het in den regel den vijfden dag of een pasarweek, in de Gonvernementslanden is het den volgenden avond; mocht er iets tusschenbeide lomen, dan wordt de tijd niet bepaald en kan dit zelfs eenige maanden daarna nog plaats vinden. Is de bruid van mindere afkomst dan de bruidegom, dan heeft juist het omgekeerde plaats, en wordt toch voor het feit, dat de bruidegom naar het huis van de bruid wordt geleid om het huwelijksfeest te vieren, dezelfde uitdrukking gebruikt. "Ngoendoeh mantoe " beteekent dat de bruid of bruidegom voor de eerste keer met haren of zijne echtgenoot bij hare of zijne sc'roonouders komt en feestelijk onthaald wordt.

Een en ander is geheel volgens de begrippen der Javanen in midden Java; in hoeverre echter dit met de wetenschap overeenkomt, laat ik geheel aan de beroegde beoordeelaars over.

Koedoes, 27 October $1878 . \quad$ TJondro Negoro.

\section{NASCHRLFT.}

Het is mij eene zeer aangename verrassing dat mijne opmerkingen in 't 3 e stuk der vierde volgreeks aanleiding hebben gegeven tot mededeelingen van de zijde van den Regent van Koedoes, den ook hier te lande zoo wel bekenden schrijver der Reizen van Poerwo Lelono. Het eenigste wat ik betreur en zeker alle belangstellenden met mij - is dat die aanteeke- 
ningen van den geëerden Schrijver zoo kort zijn. Moge hij door zijne blijvende medewerking toonen dat de geuite klacht in 't vervolg niet meer van toepassing zal wezen.

Een paar opmerkingen wenschte $i k$ hieraan toe te voegen. Ik begin met het laatste, de verklaring van nguṇd $\mathrm{nh}$ mantu. Natuurlijk neem ik gaarne aan wat de Regent van Koedoes mededeelt, maar moet dan tevens wijzen op de daarvan afwijkende verklaring van C. F. Winter. Deze toch zegt in de 16 e zamenspraak:

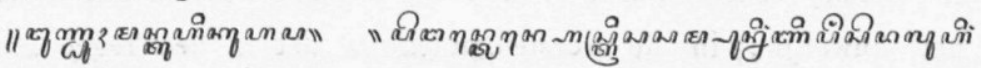

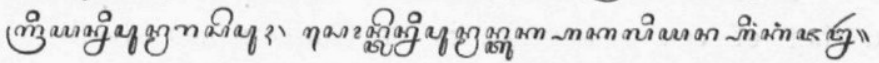

D. "Wat is nguṇ ḍ h u ant u ? " "Dat de jonggetrouwde vrouw ' 1 na een nacht ten huize harer schoonouders geslapen te hebben, den volgenden avond met haren echtgenoot (naar 't ouderlijk huis) terugkeert."

Volgens de verklaring van den Schrijver van Poerwo Lelono's Reizen verstaat men er daarentegen onder "dat de bruid voor de eerste keer met haren echtgenoot bij hare s ch o o nouders komt. "

Een van beide, ò Winter heeft gedwaald, òf het gebruik is niet overal op Java eenvormig. In de door mij aangehaalde plaats uit de Babad in proza kan er vau een halen "der bruid va n haar ouderlijk huis" ook geen sprake wezen, daar zij dat reeds verlaten had en met haren man samenwoonde.

Naar aanleiding van de voorgestelde verbetering van tĕ $\mathrm{ng}$ a h in hing tĕngah, zij opgemerkt, dat men in proza natuurlijk het laatste zou zeggen; maar het aangehaalde vers is uit de poëische Babad; daar kan tĕngah niet in hing tĕngah veranderd worden, want daardoor zou de versmaat gestoord worden.

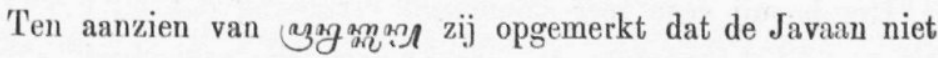
altoos het begrip van "halfbloed" er aan hecit; ik verwijs kortheidshalve naar het Handwoordenboek i. v.

H. KERN.

1 Dit is hier bedoell; het Nederlandsche woord "bruid» heb ik hier vermeden daar het tot misvatting aanleiding kan geven. 